$16^{\text {th }}$ International Conference on

AEROSPACE SCIENCES \& AVIATION TECHNOLOGY,

ASAT - 16 - May 26 - 28, 2015, E-Mail: asat@ mtc.edu.eg

Military Technical College, Kobry Elkobbah, Cairo, Egypt

Tel : +(202) 24025292 - 24036138, Fax: +(202) 22621908

\title{
Characterization and Modulation of High Power Diode Laser Module as a Target Designator
}

\author{
Tarek A. Khaled*, Ashraf F. El-Sherif ${ }^{\dagger}$, Mohamed M. Elkhatib ${ }^{\S}$
}

\begin{abstract}
In a laser tracking system (LTS) the objective is to track the reflected or scattered modulated laser beam. A four-quadrant is essentially required to center and align the optical axis of the quad detector (QD) with the main laser beam. This paper shows an experimental characterization of a high power diode laser module as a laser target designator source (LTD) used in the tracking system. It includes the (I-V) characteristic, output optical power verses driving electrical currents, slope efficiency, the laser beam profile and the wavelength dependence of temperature. Like all practical designation and tracking system, a modulation of a high power laser source with pulse repetition frequencies (PRF) mode of operation is required. So the effect of different frequencies on both of the pulse to pulse stability and wavelength stability are measured, analyzed and investigated.
\end{abstract}

Keywords: Laser modulation, Laser measurement applications, Target tracking.

\section{Introduction}

Semi-Active Laser (SAL) guidance is utilized on the modern battlefield to guide missiles and bombs toward targets. The SAL guidance scheme relies on ground-based or airborne laser designators to illuminate the target with laser energy. The reflected light from the target is then sensed by the seeker on the weapon system, typically containing a quadrant photo detector. This information is then processed, using the guidance system, to determine miss angles and computes the required corrections. In this sense, SAL seekers provide a terminal homing capability, based upon laser energy being reflected from the target, in such geometry, the in-coming radiation is detected and used for the guidance process. [1]

Early systems employing laser guidance were the Maverick, Copperhead, and Hellfire missiles which entered service in the late 1970's. These weapon systems employed semiactive laser homing seekers, operating at a wavelength of 1.06 micros, which is being used and further developed today, they are said to be semi-active because they do not emit the laser energy that passively they detect and track, in other words, the weapon system does not have a laser source installed but relies on an external laser designator. [1], because of an accurate guidance of Air to Ground missiles (AGM) and bombs is needed to hit the right targets so it's important to use a coded laser designator with pulse repetition frequency (PRF). It requires a high performance control algorithm to guide them to the intended targets. For those munitions using a laser seeker, an intelligent control system is needed to quickly guide the seeker with incoming laser reflected from targets to be tracked.

\footnotetext{
"Master Student, Egyptian Armed Forces, Cairo, Egypt/Tarekfathy81@yahoo.com

${ }^{0 \dagger}$ Prof. Dr, Egyptian Armed Forces, Cairo, Egypt/Ashraf.AlSharif@staff.aast.edu

${ }^{\S}$ Dr, Egyptian Armed Forces, Egypt/elkhatib.m@googlemail.com
} 
This paper shows experimental studies on characterization of a high power diode laser module as a laser target designator source (LTD) used in the tracking system including the (I-V) characteristic, output optical power verses drive electrical current, slope efficiency, the laser beam profile and the wavelength dependence of temperature. Like all practical designation and tracking system, a modulation of a high power laser source with pulse repetition frequencies (PRF) mode of operation is required so the effect of different frequencies on both of the pulse to pulse stability and wavelength stability are measured, analyzed and investigated.

\section{Operation principles}

\section{A. Laser beam principles}

A laser beam is a highly focused electromagnetic energy beam which can be thought of as being coherent. Coherency refers to the fact that all of the energy in the beam is at the same frequency and phase. The use of short wavelengths allow for the creation of a virtually nonspreading laser beam that can be placed onto a single entity in a target rich environment with little to no energy spill over. Laser designators radiate the narrow beam of pulsed energy, which allows for the measurement of range using the same techniques as a radar system where the pulse is sent out and the round trip time is divided by two. Many current tactical lasers operate in the near-infrared wavelength spectrum, which is not visible to the human eye. Materials chosen for the production of Continuous Wave (CW) lasers include Carbon Dioxide (CO2), Helium-Neon (He-Ne), and Argon (Ar). Materials chosen for the production of pulsed lasers include Neodymium with Yttrium Aluminum Garnet (YAG) crystals (Nd:YAG), Gallium Arsenide (GaAs), Ruby and Neodymium-Glass (Nd-Glass). Information on the CW and pulsed lasers is given in the table 1. [2]

Table1. Laser Specifications

\begin{tabular}{|c|c|c|c|c|}
\hline \multicolumn{5}{|c|}{ CONTINUOUS WAVE (CW) LASERS } \\
\hline TYPE & $\begin{array}{c}\text { WAVELENGTH, } \\
\text { nm }\end{array}$ & $\begin{array}{c}\text { POWER, } \\
\text { W }\end{array}$ & $\begin{array}{c}\text { PULSE } \\
\text { DURATION, } \\
\text { nsec }\end{array}$ & $\begin{array}{c}\text { PULSE REPETITION } \\
\text { RATE }\end{array}$ \\
\hline CO2 & 10,640 & $1400-1800$ & N/A & N/A \\
\hline He-Ne & 633 & $0.05-0.1$ & N/A & N/A \\
\hline Ar & 514 & 5 & PULSE & PULSE REPETITION \\
& & PULSED LASERS & RATE \\
\hline TYPE & WAVELENGTH, & POWER, & DURATION, nsec & 100 sec-1 \\
\hline Nd:YAG & 1064 & $0.02-0.04$ & $10-25$ & 100 sec-1 \\
\hline GaAs & 900 & 0.0001 & $100-150$ & 20 min-1 \\
\hline Ruby & 694 & $7-9$ & $3-5$ & 12 hr-1 \\
\hline Nd-glass & 530 & $20-30$ & 20 & W \\
\hline
\end{tabular}


The light amplification by stimulated emission of radiation (laser) is the enabling technology of more precise guided weapons. Laser systems enable joint forces to engage a wider range of targets with more accuracy and fewer munitions than previously possible. [3]

Laser designators emit a narrow beam of laser pulses which is susceptible to degradation from atmospheric scatter and a variety of target reflections [3]. Laser designators and optical seekers use a pulse coding system to ensure that a specific seeker and designator combination work in harmony. By setting the same code in both the designator and the optical seeker, the seeker will track only the energy with the correct coding. The pulse coding is based on pulse repetition frequency (PRF) [3].

Illustrates IR and laser equipment compatibility is shown in Fig. 1. As depicted, compatibility exists only between Laser Target Detection Systems (LTDs) and Laser Spot Tracking systems (LSTs). In other words, all coded laser target designators can work with all coded laser acquisition and/or spot trackers and all coded laser-guided weapons.

IR pointers and night vision goggles (NVGs) are only compatible with each other. IR pointers cannot designate for LSTs, and NVGs cannot see the LTD mark. Forward-looking infrared (FLIR) systems are not compatible with LTDs, LSTs, and/or IR pointers [3].

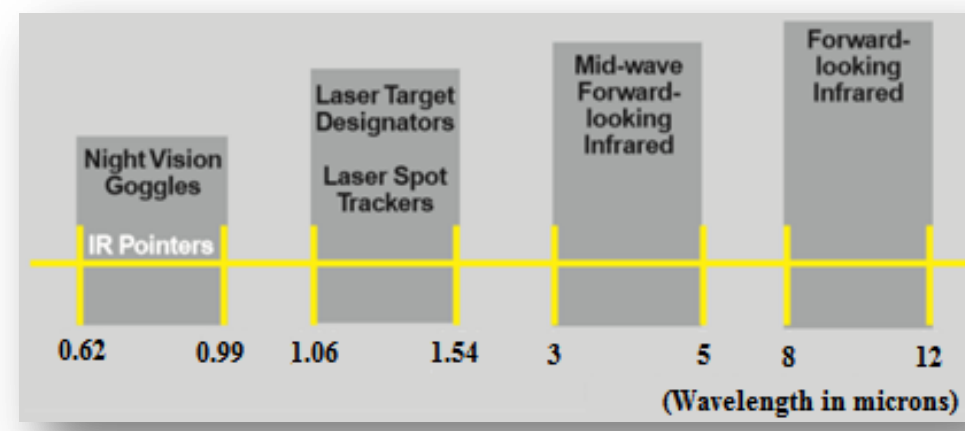

Fig.1. Infrared Electromagnetic Spectrum

\section{B. Quad detector structure and principles}

The invention is generally directed to a Laser Spot Tracking System (LSTS) to simultaneously process multiple targets with position and code data. Laser spot trackers have been used for many years to steer a guided weapon system onto target. Typically a pulsed narrow beam laser illuminates the target then the laser light is scattered from the target. The tracker or seeker lens collects the some of the scattered light and condenses it into a spot. The tracker is steered until the spot is divided equally into four equal signals normally using a quad detector shown in Fig.2 $(\mathrm{a}, \mathrm{b})$ the null position. In this position the tracking head bore sight is pointed at the target [4].

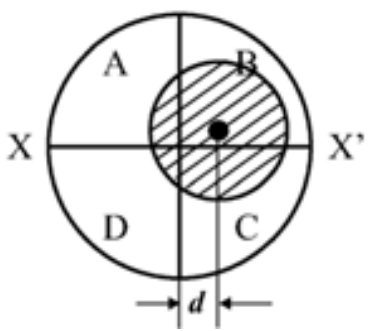

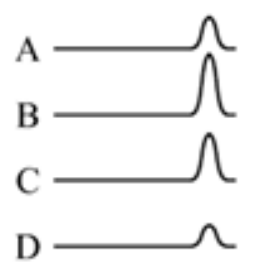

Fig.2 (b)
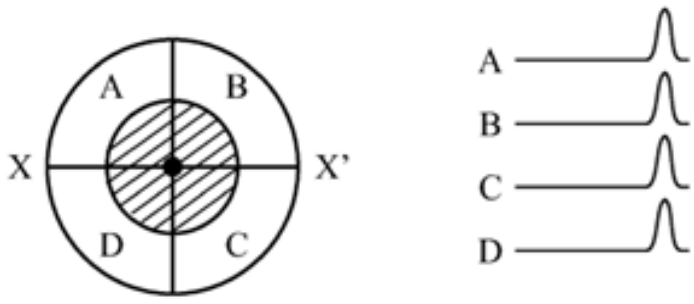

Fig.2 (a)

Fig.2 .The quad detector principle of operation 


\section{Electrical Characterization of the High power Diode Laser Module}

\section{A. Exprimental setup}

A high power diode laser fiber coupled module model (VDM00231) operating at $980 \pm 2$ $\mathrm{nm}$ which has a maximum $\mathrm{CW}$ output power up to $4 \mathrm{~W}$ under maximum input driving current at

an integrated highly precise temperature controller model (UM series DiTec, Jenoptik) used for driving diode lasers in CW or pulsed mode as it has an On-Board Oscillator which can be freely configure for pulsating the laser, power supply (output $24 \mathrm{~V}, 10.5 \mathrm{~A}$ ) and a fiber cable are used to measure the electrical characterization of the high power diode laser module as shown in Fig. 3.

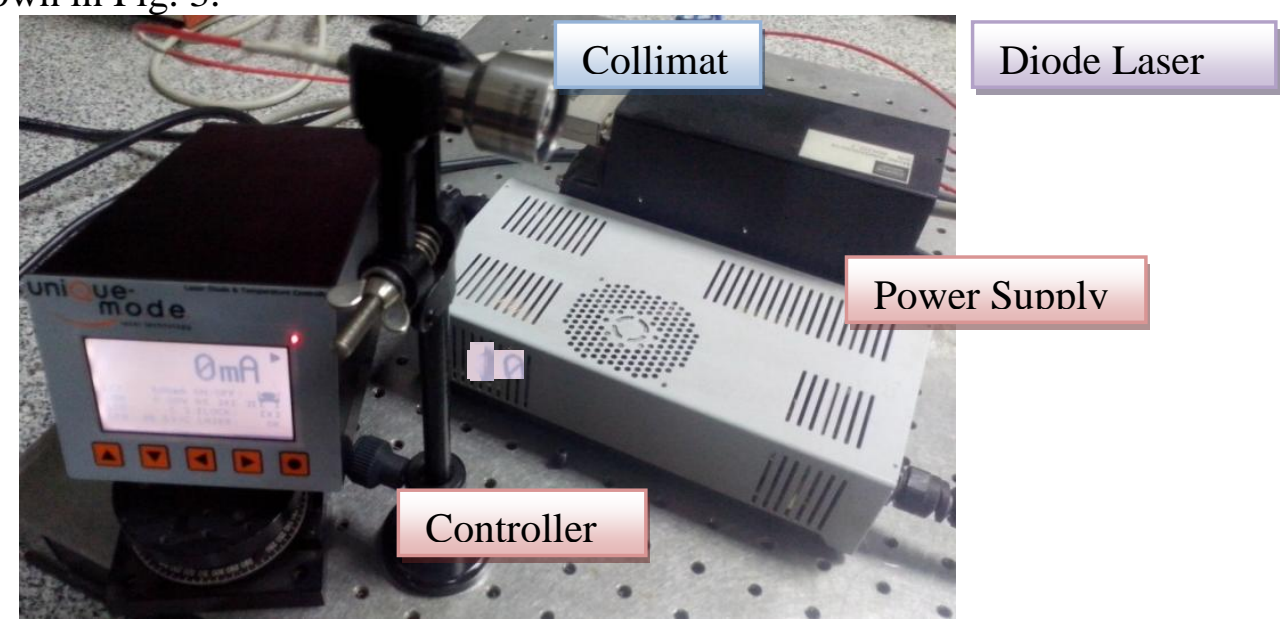

Fig.3 .The photograph of the diode laser system

The highest brightness is achieved by transforming the asymmetric radiation from the laser diode into a symmetrical beam, using micro optics and finally this beam can be coupled into $125 \mu \mathrm{m}$ fiber with core diameter of $50 \mu \mathrm{m}$ [5].

\section{B. Electrical Mesurments Results}

By adjusting the laser diode driver to different currents then obtaining the driving input voltages to the diode module (measured and viewed through the controller screen) at different operating temperatures; the measured electrical (I-V) diode characteristic curve is obtained at different temperatures $20,25,30$ and $35^{\circ} \mathrm{C}$ as shown in Fig.4.

The measured electrical (I-V) diode characteristic curve shows that the laser diode module is a temperature independent which means that the unit is electrically stable by having a liner relation between the diode laser current and voltage. 


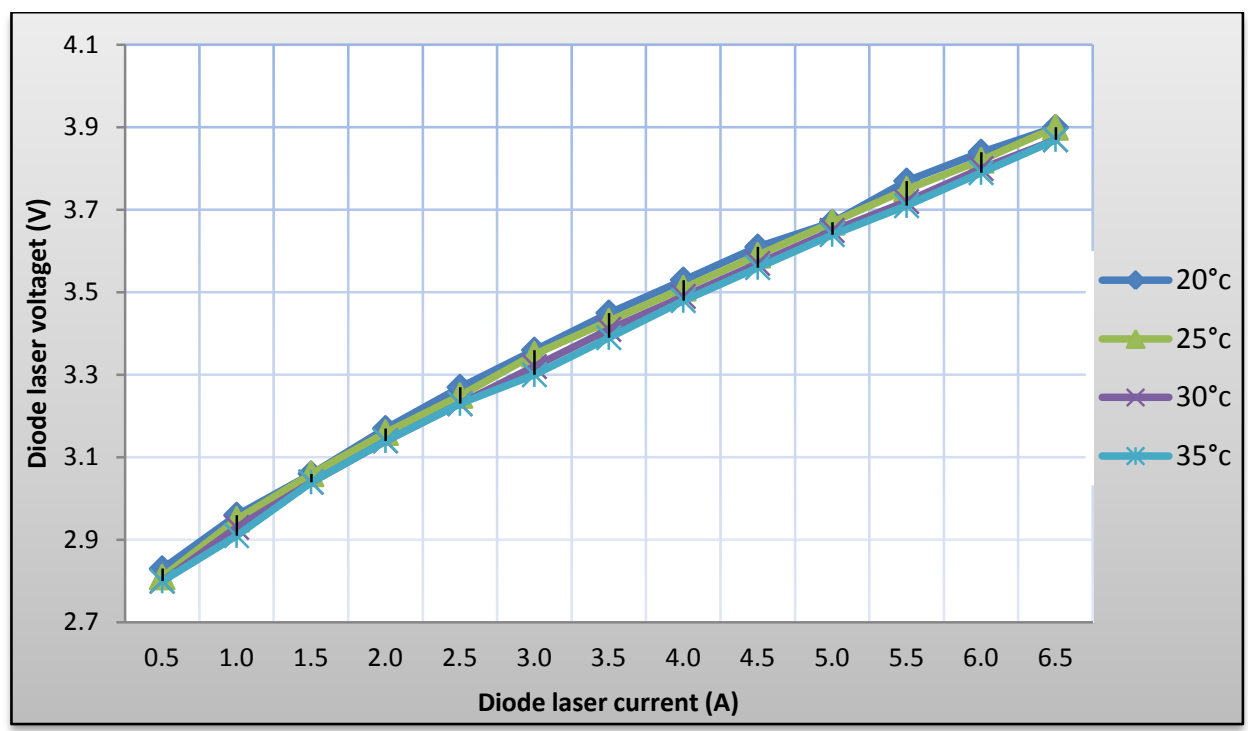

Fig. 4.The (I-V) characteristic curve at different temperatures

Also an electrical power characteristic curve is obtained by operating different currents at different temperatures shows that the electrical output power is a temperature independent which means that the unit is also electrically stable by having a liner relation between the diode laser current and the electrical power as shown in Fig.5.

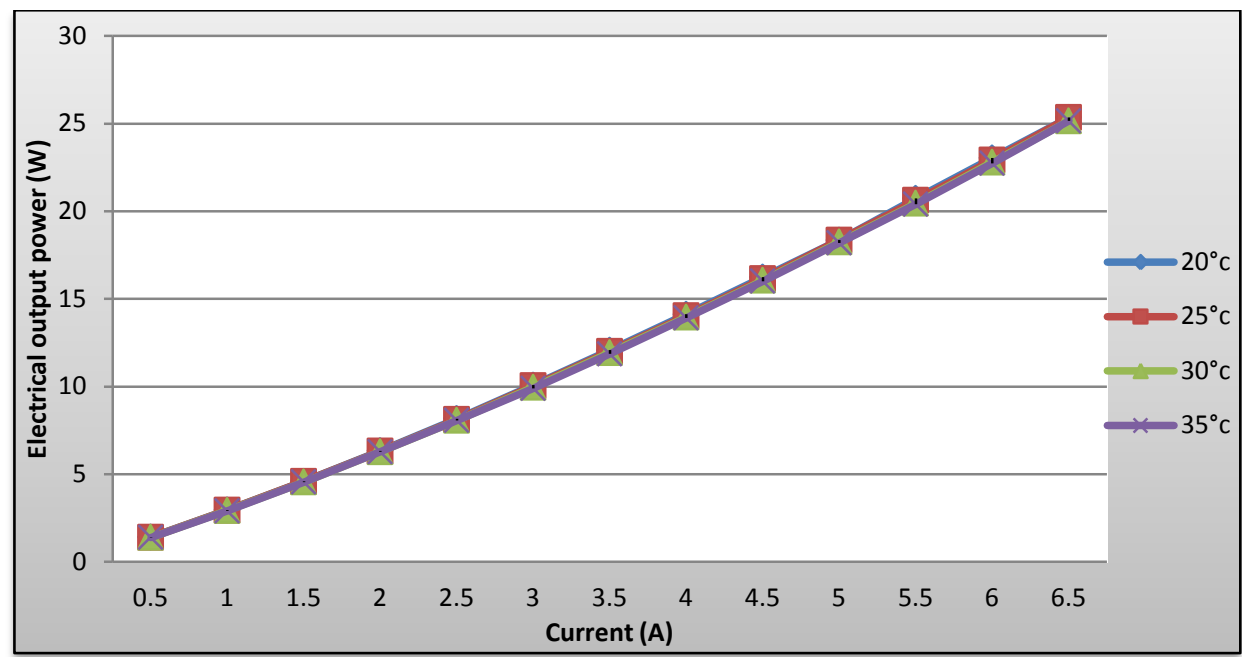

Fig. 5. Electrical characteristics curve at different temperatures.

The electrical output power of semiconductor diode laser was measured as a function of the driver input current (I); which is temperature independent. The turning point at which the laser output abruptly starts to increase corresponds to the threshold lasing point. The threshold current $\left(\mathrm{I}_{\mathrm{th}}\right)$ or equivalently threshold current density $\left(\mathrm{J}_{\mathrm{th}}\right)$ is an important device parameter and its minimization is desirable. It is well known that when the input current $\mathrm{I}<\mathrm{I}_{\text {th }}$; light output mainly consists of spontaneous emission only.

\section{Optical Characterization of the High power Diode Laser Module}

\section{A. Exprimental setup}

An optical power meter system model (PM100D, Thorlabs) and an integrating sphere photodiode high power sensor model (S142C, Thorlabs) for detection of light signals 
from 350 to $1100 \mathrm{~nm}$ range are used to measure an optical power ranging from 50nW $500 \mathrm{~mW}$ as shown in Fig. 6.

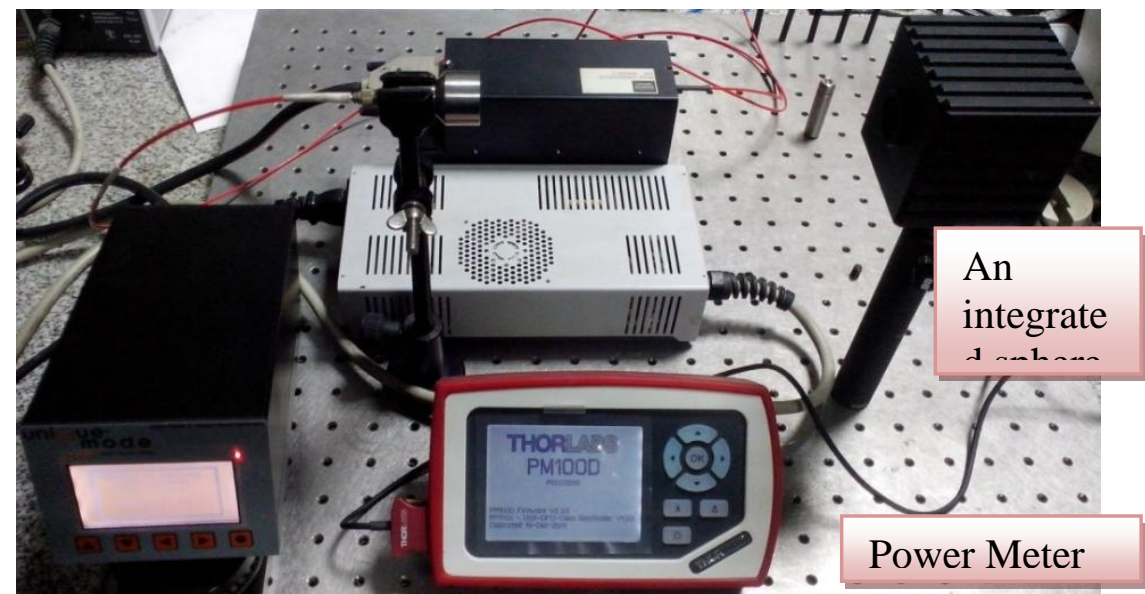

Fig. 6.Photograph of the experimental setup

\section{B. Optical Mesurments Results}

The output optical laser power at different operating temperatures is measured using the optical power meter and the integrating sphere photodiode high power sensor; corresponding to the change in the driving input current to the diode laser module. We have measured the diode output laser power in (Watt) versus the diode input driving current in (Ampere) at different temperatures of $20,25,30$ and $35^{\circ} \mathrm{C}$.

The optical power characteristic curve was plotted at different temperatures showing the temperature effect on the threshold lasing point and the linear relation between the output optical laser power and the input driving current behind threshold point, as the laser operated continuously without any indication of heating or failure and the results illustrate that the laser threshold output is slightly increasing with the temperature.

The Optical characteristics curve of the high power diode module at different of operating temperatures was investigated to determine the highest power of $1.88 \mathrm{~W}$ that can be achieved at a certain temperature of $35^{\circ} \mathrm{c}$ and a driving current of $6.5 \mathrm{~A}$ as shown in Fig.7.

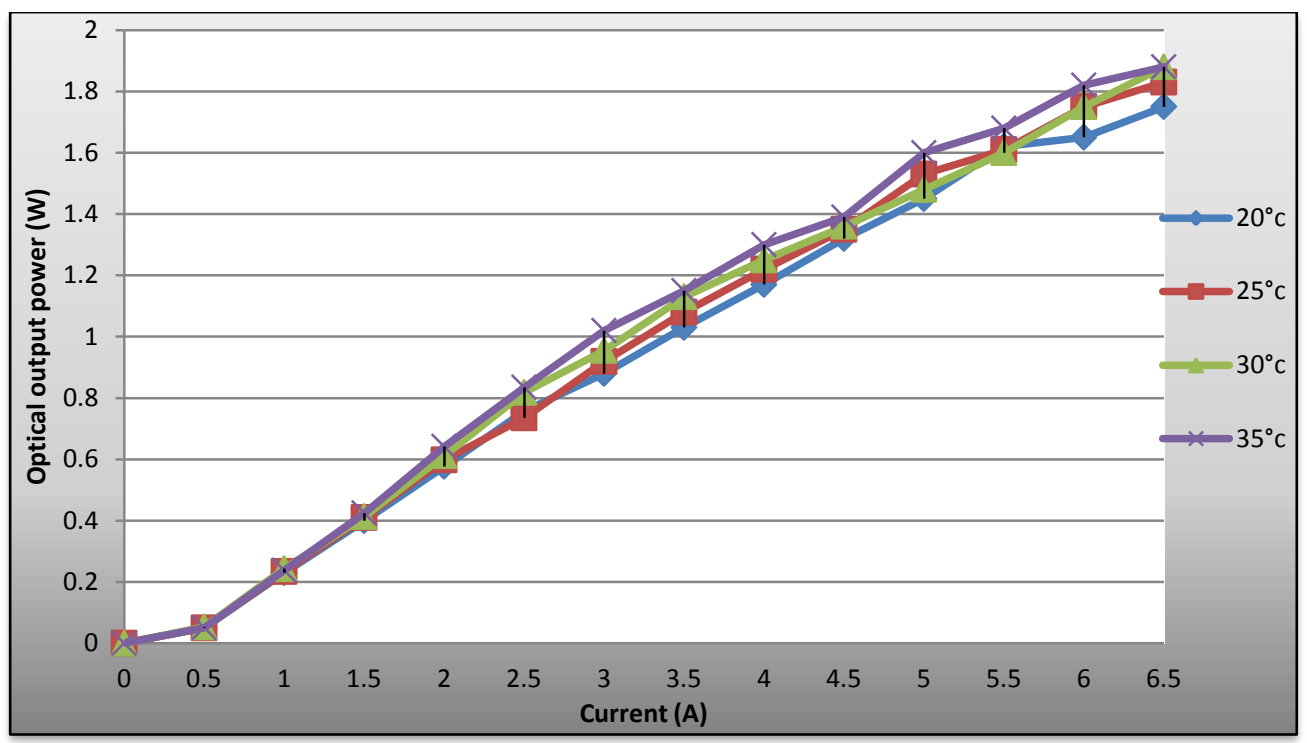

Fig. 7.The optical characteristics curve at different operating temperatures. 
The conversion efficiency of the diode laser was found by plotting the output optical power from the pigtail fiber coupled diode module and the electrical power at different driving currents and different temperature as shown in Fig. 8.

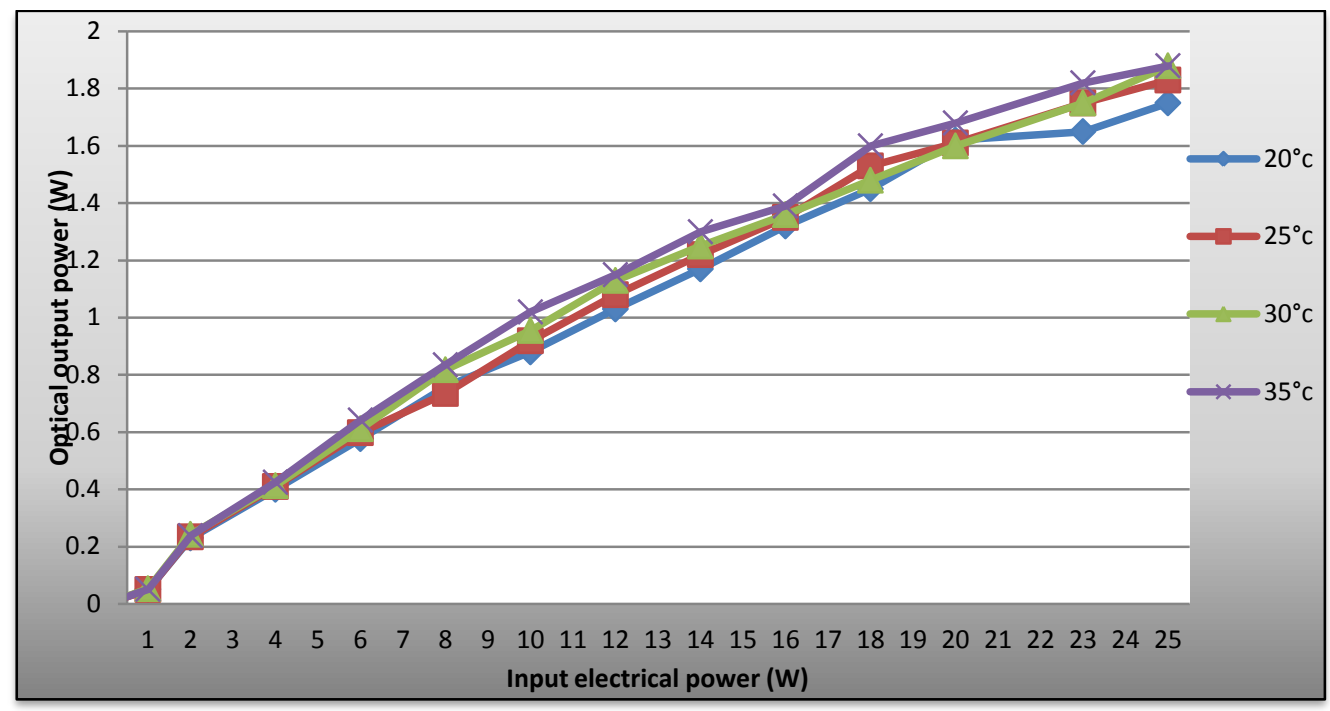

Fig. 8.The Optical characteristics (L-I) curve of the high power diode module

From the measurements shown in Fig. 7 and Fig. 8, the maximum slope efficiency is around $25 \%$ at a wavelength of $980 \mathrm{~nm}$. The decreasing in the measured slope efficiency with increasing pumping current shown in Fig. 9 occurs because of the ohmic losses in the diode laser increasing with the square of the current [5]; where the output electrical power is in linear relation with the driving current as shown in Fig. 5.

From these experimental results it is clear that at temperature of $35^{\circ} \mathrm{C}$, the (L-I) curve has the highest threshold value with the lowest conversion electrical to optical slope efficiency in this case.

From the temperature effect on both of threshold lasing and the conversion slope efficiency; taking into account the measuring results of the electrical characterization shown in Fig.

5 .

The operation of the high power diode laser module at temperature of $35^{\circ} \mathrm{C}$ was the best condition, it gave the higher slope efficiency with lower consumption of electrical power and lower threshold lasing which considered to be an optimum condition producing a maximum output performance at temperature of $35^{\circ} \mathrm{C}$ as shown in Fig. 9. 


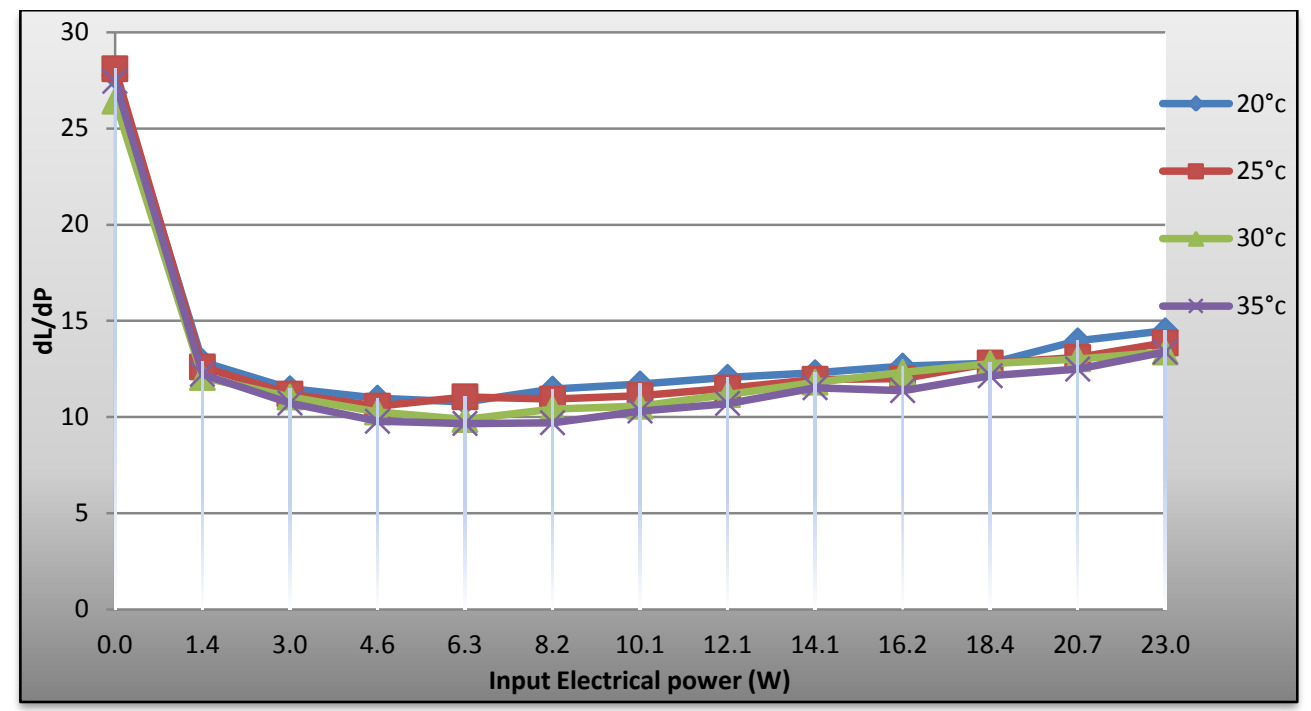

Fig. 9. Different slope efficiencies at different temperatures.

\section{Temperature effects on the wavelength measurements in $\mathrm{CW}$ laser mode}

\section{A. Exprimental setup}

A high resolution spectrometer model (NIRQUEST) that covers the wavelength range from 900-2500 nm, fiber optic cable, collimated optics, high power pigtail diode laser module and "Spectra Suite" computer software are used to measure the wavelength as shown in Fig. 10.

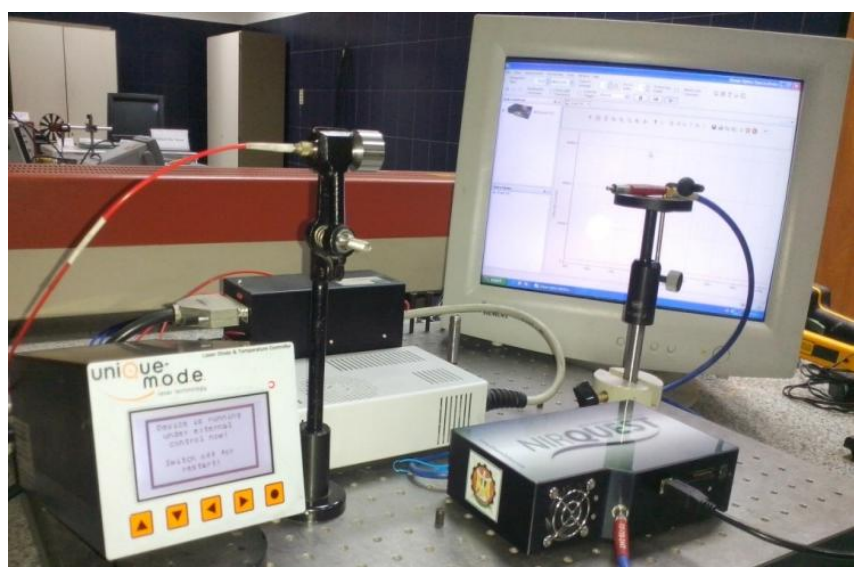

Fig. 10.Photograph of the experimental setup

\section{B. Optical Mesurments Results}

The spectrum of the high power diode laser module for different driving currents from $0.5 \mathrm{~A}$ to $7 \mathrm{~A}$ at different temperatures from $25{ }^{\circ} \mathrm{C}$ to $35^{\circ} \mathrm{C}$ controlled by the laser diode driver is measured, recorded and investigated, the result is typically as shown in Fig. 11 (a-d). 


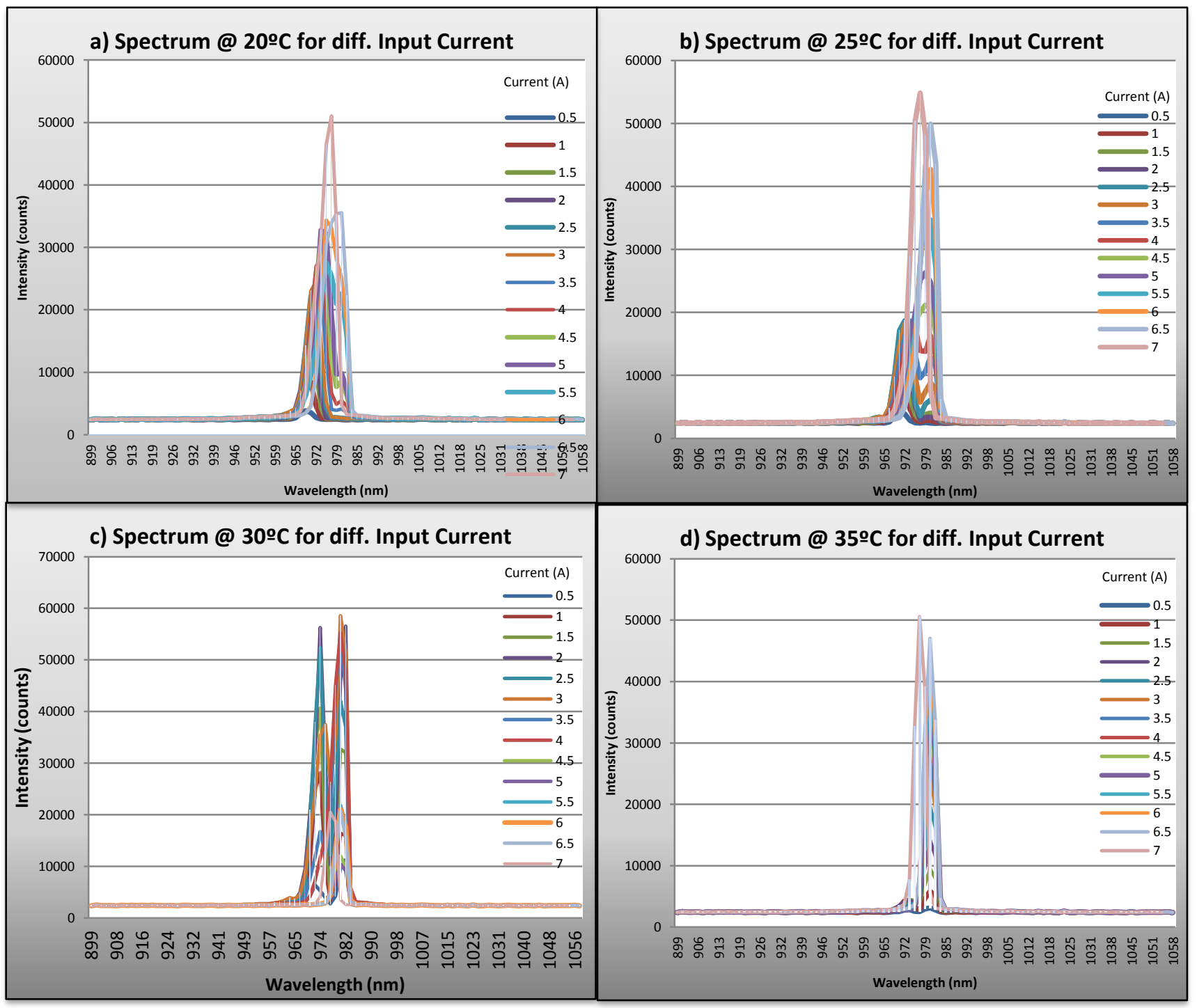

Fig. 11 The spectrum of the $980 \mathrm{~nm}$ high power diode laser with different currents operating at different temperatures $(\mathrm{a}) 20^{\circ} \mathrm{C}, \quad(\mathrm{b}) 25^{\circ} \mathrm{C}, \quad(\mathrm{c}) 30^{\circ} \mathrm{C}, \quad$ (d) $35^{\circ} \mathrm{C}$

From the above experiments and measurements that are illustrated in Fig.11, It was noticed that the wavelength will slightly change; doubled mode with respect to the temperature variation in the output wavelength at $9 \wedge \cdot .34 \mathrm{~nm}$ which mean that the emitted laser wavelength is affected by the temperature increasing and being shifted by the current increment. This experiment was maintained to investigate the stability of the unit used.

It can be observed that the best operating temperature for the diode laser with respect to wavelength $980 \mathrm{~nm}$ is at temperature of $35^{\circ} \mathrm{C}$ because it's one mode without any shift for all the driving current from $0.5 \mathrm{~A}$ to $6.5 \mathrm{~A}$; although it was being shifted from the central wavelength

$980 \mathrm{~nm}$ at the current of 7A.

\section{The beam profile of the high power diode laser module}

The TEM00 laser mode with a high efficiency, high output power, good spatial beam profile and good stability is highly desired in the quad detector tracking system so a thermal camera is used to capture the thermal image showing the optical output Gaussian shape at a distance of $7 \mathrm{~m}$ from the high power diode laser module. 


\section{A. Exprimental setup}

A high power diode laser fiber coupled module model (VDM00231) operating at $980 \pm 2$ $\mathrm{nm}$,

an integrated highly precise temperature controller model (UM series DiTec, Jenoptik), power supply (output 24V, 10.5A), a fiber cable as shown in Fig. 3; and a thermal camera model (Ti20, Fluke Thermal Imager) are used to investigate a beam profile.

\section{B. Optical Mesurments Results}

A thermal image of a laser beam at a stabilized wavelength of $980 \mathrm{~nm}$ is produced by using the thermal camera on a target at a distance of $7 \mathrm{~m}$ away from a the laser source, this thermal image has the shape of a Gaussian beam profile as shown in Fig. 12.
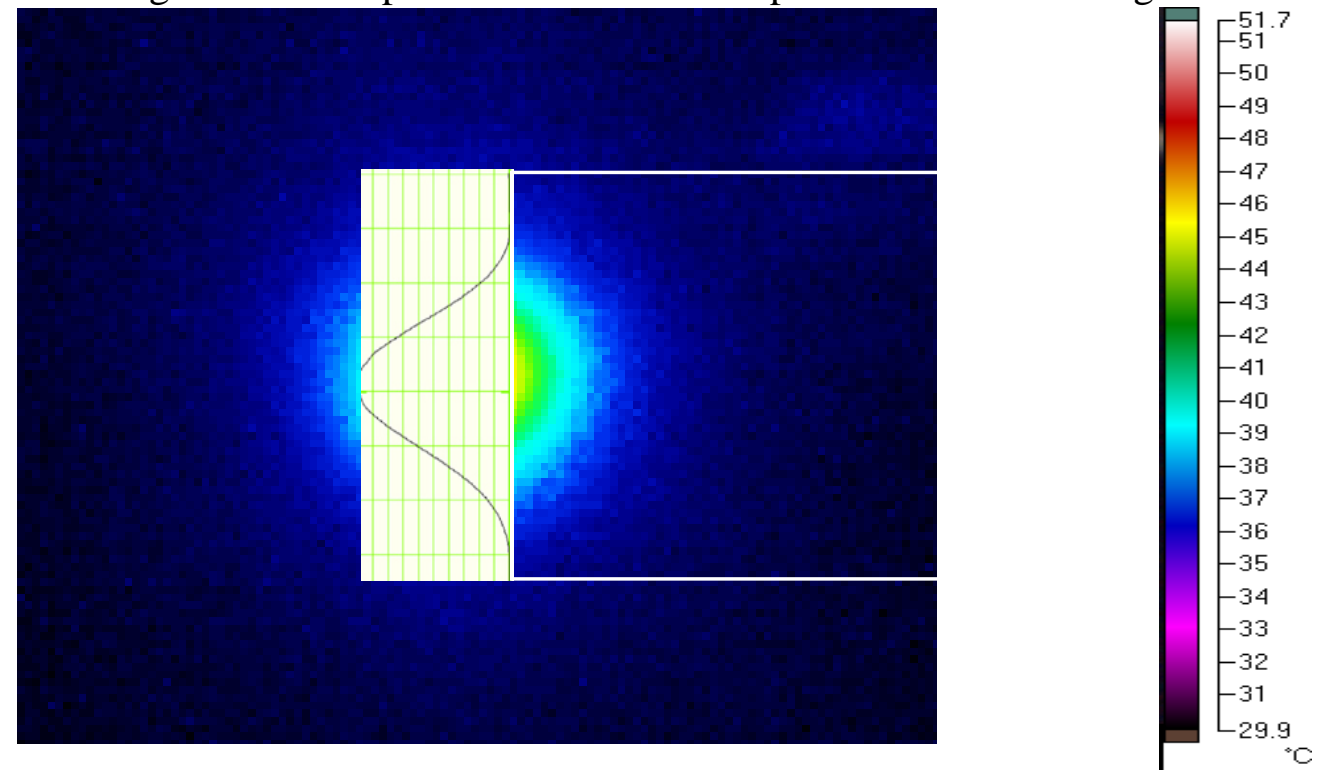

Fig. 12 Output beam profile of diode laser module with a stabilized wavelength at 980 nm.

\section{Laser modulation with different pulse repetition frequencies (PRF)}

Laser designators and seekers use a pulse coding system to ensure that a specific seeker and designator combination work in harmony. By setting the same code in both the designator and the seeker, the seeker will track only the target illuminated by the designator. The pulse coding used by all systems is based on Pulse Repetition Frequency (PRF). [6]

Coding allows simultaneous or nearly simultaneous attacks on multiple targets by a single aircraft, or flights of aircraft, dropping Laser Guided Weapon (LGW) set on different codes. This tactic may be employed when several high-priority targets need to be attacked expeditiously and can be designated simultaneously by the supported unit(s). [6]

\section{A. Exprimental setup to investigate the pulse to pulse stability}

A signal generator model (33500B series, Agilent Tec.) which is connected externally to a controller to pulsate the diode laser, photo detector model (DET10C, THORLABS) which is a biased Indium Gallium Arsenide (InGaAs) detector designed and an oscilloscope model (DSO-X 3052A, Agilent Tec) are used to investigate the pulse to pulse stability as shown in Fig.13. 


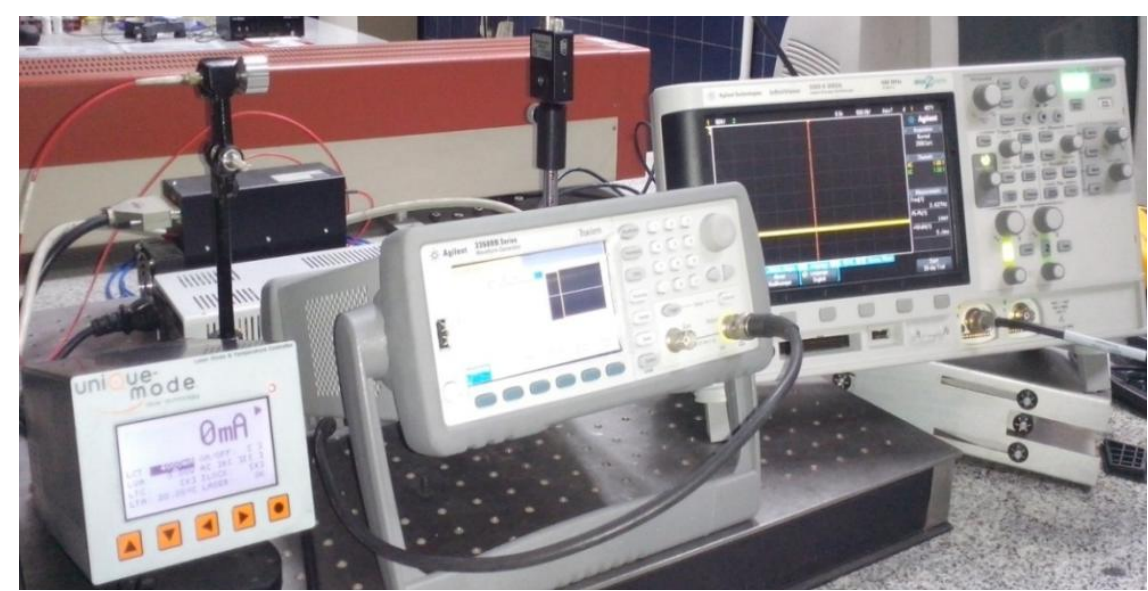

Fig. 13 Photograph of the experimental setup

\section{B. Mesurments procedures and Results}

By using the main experimental setup, the responsivity of the output diode laser using different frequencies $5,10,15,20,25 \mathrm{~Hz}$ (the most frequencies used in the military applications) can be investigated by monitoring the laser output on the oscilloscope as shown in Fig.14 (a-e).

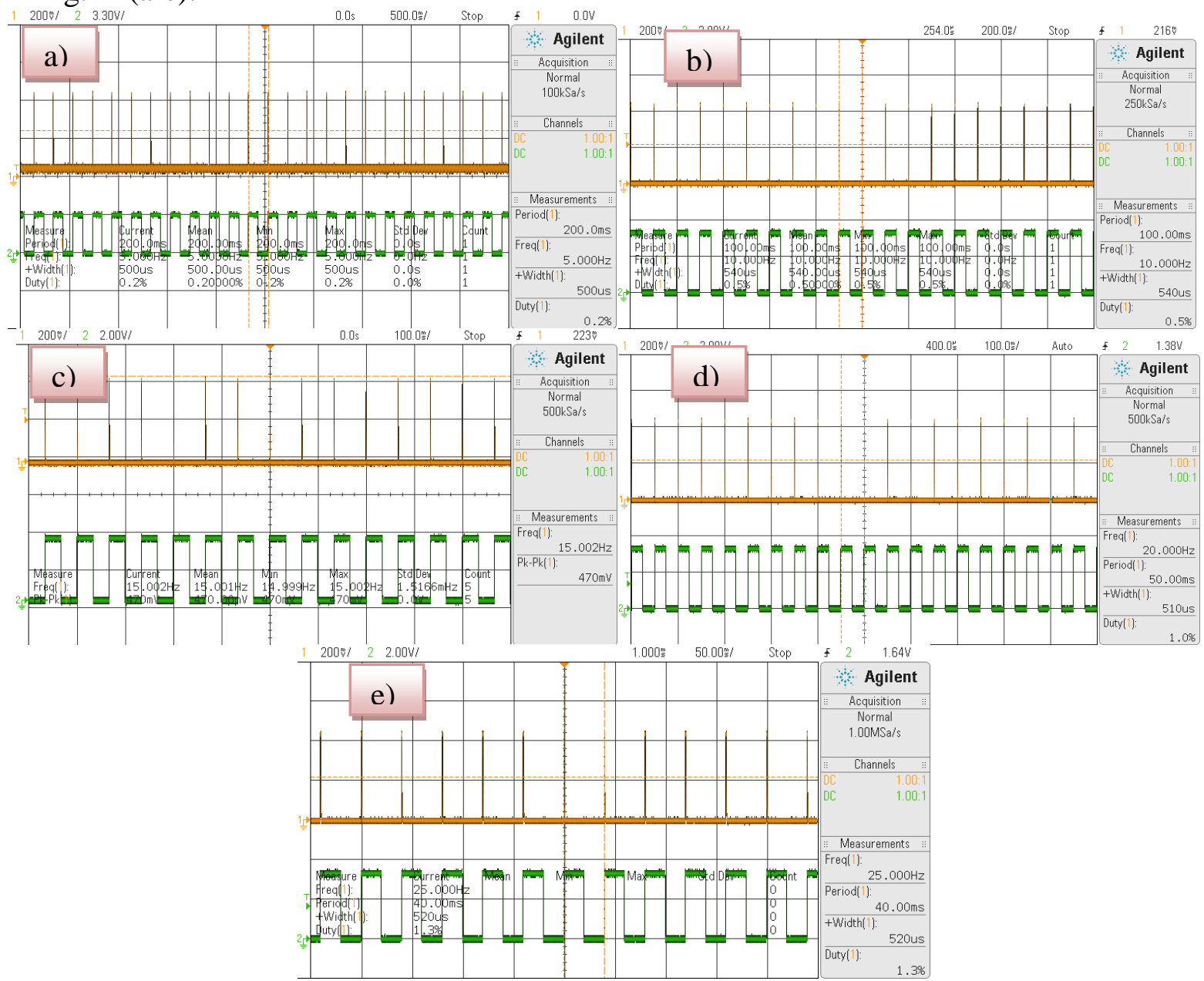

Fig. 14 Laser pulse trace at frequency of (a) $5 \mathrm{~Hz}$, (b) $10 \mathrm{~Hz}$, (c) $15 \mathrm{~Hz}$, (d) $20 \mathrm{~Hz}$, (e) $25 \mathrm{~Hz}$

The responsivity of the output diode laser versus different frequencies has been investigated,

it was found that it has a high pulse to pulse stability more than $90 \%$ at all frequencies ranges from $5 \mathrm{~Hz}$ to $25 \mathrm{~Hz}$ like a clearly pulse trace at a frequency of $10 \mathrm{~Hz}$ shown in Fig. 15. 


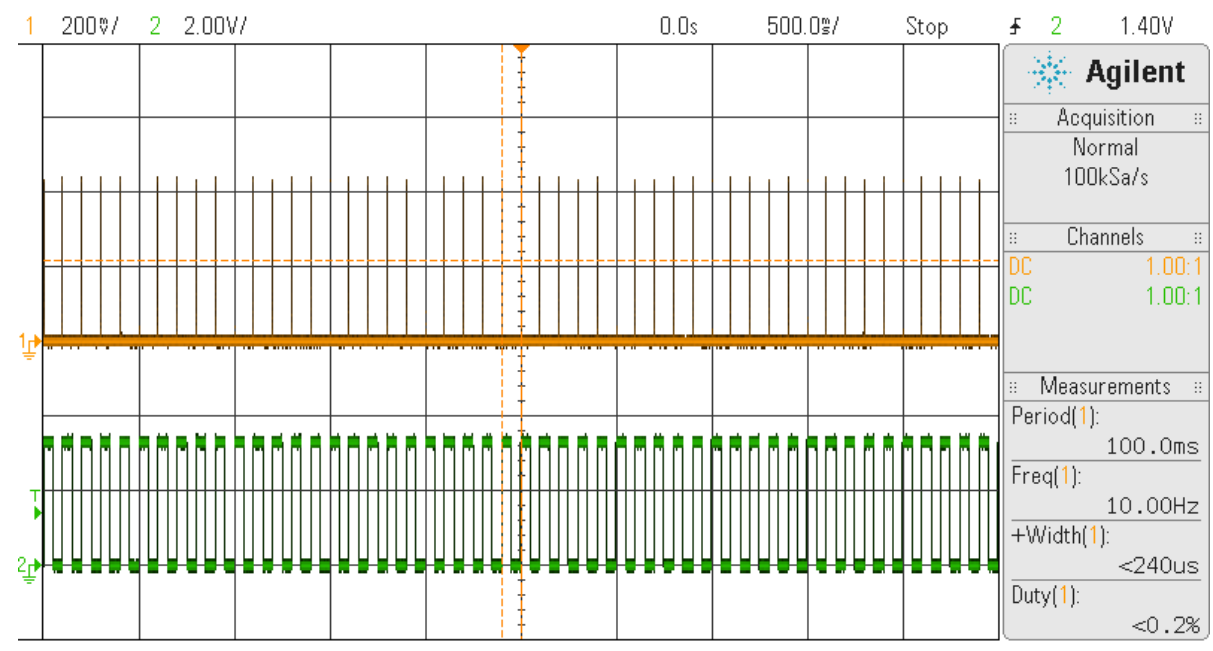

Fig. 15 Laser pulse trace at frequency of $10 \mathrm{~Hz}$

\section{Exprimental setup to investigate the wavelength stability at pulsed mode of operation}

A high resolution spectrometer model (NIRQUEST), fiber optic cable, collimated optics and "Spectra Suite" computer software shown in Fig. 10 with the test System experimental main setup shown in Fig.13 are used to investigate the wavelength stability.

\section{Mesurments procedures and Results}

The wavelength stability has been investigated by using a high resolution spectrometer while adjusting the signal generator to different frequencies $5,10,15,20,25 \mathrm{~Hz}$ (the most frequencies used in the military applications) at different temperatures then measuring and recording the result using the "Spectra Suite" computer software as given in the table 2.

Table 2.Recorded results of wavelength

\begin{tabular}{|r|c|c|c|c|}
\hline & \multicolumn{4}{|c|}{ Temperature $\left({ }^{\circ} \mathbf{C}\right)$} \\
\cline { 2 - 5 } & $\mathbf{2 0}$ & $\mathbf{2 5}$ & $\mathbf{3 0}$ & $\mathbf{3 5}$ \\
\hline Frequency $(\mathrm{Hz})$ & \multicolumn{5}{|c|}{ Wavelength(nm) } \\
\hline 5 & 970.44 & 973.74 & 981.99 & 973.74 \\
\hline 10 & 970.44 & 975.39 & 975.39 & 981.99 \\
\hline 15 & 970.44 & 973.74 & 975.39 & 981.99 \\
\hline 20 & 970.44 & 973.74 & 975.39 & 981.99 \\
\hline 25 & 970.44 & 973.74 & 975.39 & 981.99 \\
\hline
\end{tabular}

The most stable wavelength has been achieved at a certain temperature which is $20^{\circ} \mathrm{C}$, the moderate wavelength stability is at temperature $25^{\circ} \mathrm{C}$ and the lowest wavelength stability is at temperature of $30^{\circ} \mathrm{C}$ and $35^{\circ} \mathrm{C}$ (best stability at temperature of $35^{\circ} \mathrm{C}$ starting from a frequency of $15 \mathrm{~Hz}$ ) as shown in Fig. 16. 


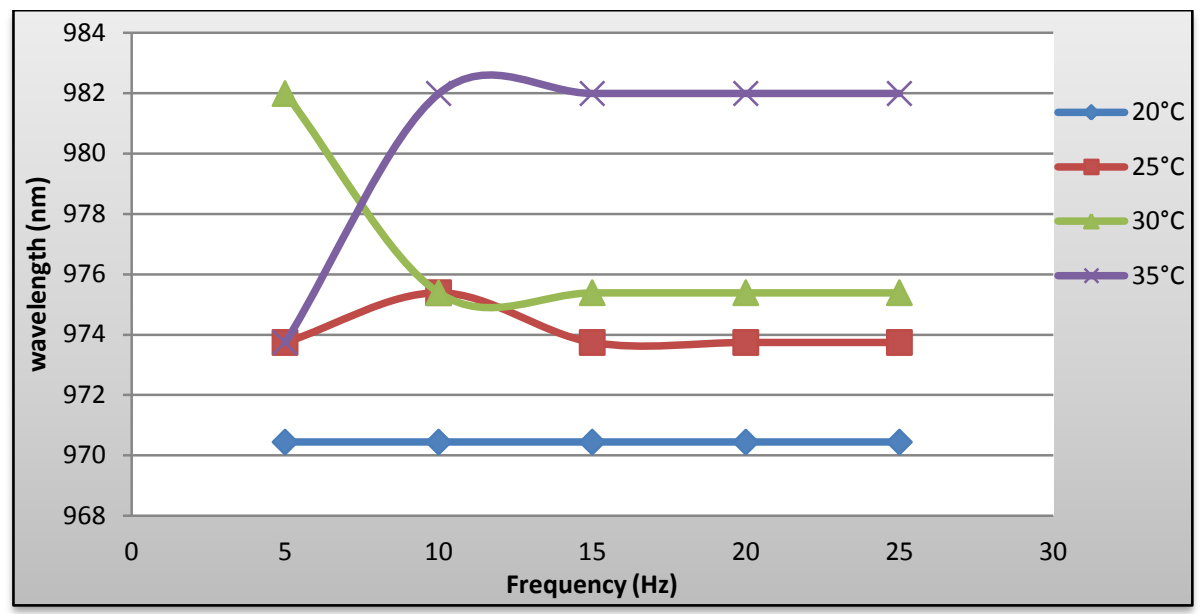

Fig .16 The wavelength stability

\section{Conclusion}

Experimental studies on the operation and the optical characteristics curve of the high power diode laser module at different operating temperatures is investigated and characterized to be used at a designation and tracking system in order to determine the highest power of $1.88 \mathrm{~W}$ that can be achieved at a certain temperature of $35^{\circ} \mathrm{C}$ at a driving current of $6.5 \mathrm{~A}$, It gave the higher slope efficiency with lower consumption electrical power and lower threshold lasing. The high power diode laser module operating at wavelength of $980 \mathrm{~nm}$ and temperature of $35^{\circ} \mathrm{C}$ or a wide range of driving current ranges from $0.5 \mathrm{~A}$ to $6.5 \mathrm{~A}$. The laser pulse to pulse stability of more than $90 \%$ is investigated at a driving current of $6.5 \mathrm{~A}$ and the highest power of $1.88 \mathrm{~W}$ at all frequencies range from $5 \mathrm{~Hz}$ to $25 \mathrm{~Hz}$.

The highest wavelength stability is determined at a temperature of $20^{\circ} \mathrm{C}$ and it is stabilized at all frequencies ranged from $5 \mathrm{~Hz}$ to $25 \mathrm{~Hz}$, the lowest wavelength stability is determined at a temperature of $30,35^{\circ} \mathrm{C}$ and it is stabilized at frequencies ranged from $15-25 \mathrm{~Hz}$. Finally, the optimum performance of the high power diode laser module of $1.88 \mathrm{~W}$ operating at wavelength of $980 \mathrm{~nm}$ is achieved at temperature of $35^{\circ} \mathrm{C}$ and frequencies ranges from $15 \mathrm{~Hz}$ to $25 \mathrm{~Hz}$ with a high pulse to pulse stability of more than $90 \%$.

\section{References}

1.G.Katulka, et al., Development and charactrization of low cost seeker technology for us army applications, in OMB No. 0704-01882008.

2.Class Notes: Tri-Mode Seeker Technologies - UAH Professional Development - Berinato 2003

3.Joint Tactics, Techniques, and Procedures for Laser Designation Operations, D. Joint Chiefs of Staff Washington, Editor 1999. p. 149.

4.Crawford, I.D., et al., Laser spot tracker and target identifier, 2010, Google Patents.

5.W. Streifer, D.S., G. Harnagel, D. Welch, J. Berger, and M. Sakamoto, Advances in Diode Laser pumps.

Quantum Electronics, 1988. 24.

6.Joint Laser Designation Procedures (JLASER), D. Joint Chiefs of Staff Washington, Editor 1991. 